Bull. Egypt. Soc. Physiol. Sci. 37(2), 189-198

\author{
Bull. of Egyp. Soc. Physiol. Sci. \\ (Official Journal of Egyptian Society for Physiological Sciences) \\ (pISSN: 1110-0842; eISSN: 2356-9514)
}

\title{
Disturbed Inflammatory/Anti-inflammatory Milieu and Activation of Primary Phase \\ Reactants may Underlie Development and Recurrence of First trimester Pregnancy \\ Loss
}

\author{
${ }^{1}$ Mohamad F. Al-She rbeny MD \& ${ }^{2}$ Manal M. Hassaan MD \\ ${ }^{1}$ Department of Obstetrics \& Gynecology, Faculty of Medic ine, Benha University \\ ${ }^{2}$ Department of Medical Biochemistry, Faculty of Applied Medical Sc iences, Oct.6 University
}

Received: 13 May 2017

Accepted: 15 June 2017

A vailable online: $1 \mathrm{Ju}$ ly 2017

\section{Keywords}

First trimester pregnancy

loss

Inflammatory cytokines

Alpha-1 antitrypsin
Abstract

Objectives: Estimation of serum levels of tumor necrosis factor- $\alpha$ (TNF- $\alpha$ ), interleukin (IL-) 6 and 10 and alpha-1 antitrypsin (AAT) in pregnant women with current pregnancy loss (CPL) and nonpregnant women with history of recurrent PL (RPL) compared versus women with normal pregnancy (NP). Patients \& Methods: All studied women underwent clinical and vaginal ultrasonographic examination for assurance of inclusion criteria and then gave blood samples for ELISA estimation of studied parameters. Results: Patients of CPL and RPL groups showed significantly high serum TNF- $\alpha$ and IL-6 levels with significantly lower serum IL-10 levels than women of NP group with significant difference between CPL and RPL groups. Serum AAT levels were significantly lower in CPL group than RPL and NP groups with significantly lower levels in RPL than NP group. High serum TNF- $\alpha$ and low AAT levels showed high positive predictive value (PPV) and sensitivity, respectively, for possibility of presence or recurrence of PL. Conclusion: Disturbed serum levels of pro- and anti-inflammatory cytokines could diagnose CPL with high PPV and persistence of their disturbed levels may predispose to RPL. Activation of primary phase reactant system may underlie, accompany or initiate PL, so low serum AAT during $1^{\text {st }}$ trimester and its persistently low serum levels during inter-pregnancy intervals could be used as screening test for presence or liability for development of PL.

Corres ponding author: Dr. Manal M. Hassaan, Department of Medical Biochemistry, Faculty of Applied Medical Sciences, Oct.6 University: Email: 151239@o6u.edu.eg: Mob \# :+2 01001682254 


\section{Introduction}

Recurrent pregnancy loss (RPL), commonly defined as 3 consecutive losses at $<10$ weeks gestation, affects up to $5 \%$ of couples (1). The medical evaluation of RPL is mainly focused on maternal factors (2). Well-accepted causes include uterine malformation, antiphospholipid syndrome, and parental chromosomal abnormalities; however, up to $75 \%$ of RPL cases are idiopathic (1).

Successful pregnancy relies on the accurate regulation of the maternal-fetal immune system, without enough tolerance in the uterine microenvironment, the mother and fetus could not peacefully coexist (3). Balanced immune responses are required for the maintenance of successful pregnancy and innate immune disturbances may be responsible for some adverse pregnancy outcomes including recurrent spontaneous abortion (4).

Regulatory $\mathrm{T}$ cells and $\mathrm{T}$ helper 17 cells are two distinct subsets of CD4+ $\mathrm{T}$ cells, which are mutually antagonistic in the immune response, but their dysregulation may play a role in pathogenesis of unexplained recurrent spontaneous abortion (5). Moreover, limited information is available on the balance state of pro- and anti-inflammatory cytokines in patients with recurrent implantation failure (6).

Alpha-1 antitrypsin (AAT) is a glycoprotein, serine protease inhibitor that is abundant in plasma (7). AAT is the prototypical protease inhibitor from the serine protease inhibitor superfamily that protects tissues from proteolytic damage (8). AAT exhibits immunomodulatory properties in several T-cell-dependent immune pathologies (9). AAT molecule is predominantly produced in the liver (10), but was produced locally by human amniotic epithelial cells (11). AAT rises during acute phase responses and healthy pregnancies (9). AAT in the amnion may function as a protective shield at inflammatory sites, and it loses its inhibitory activity in cases with preterm premature rupture of the membranes possibly by oxidation (12). Moreover,

\section{Hypothesis}

The hypothesis of the study is that disturbed proinflammatory/anti-inflammatory relationship may underlie pathogenesis of RPL with a possible role of primary phase reactants for induction of 1 st trimester RPL.

\section{Objectives}

Evaluation of serum levels of tumor necrosis factor- $\alpha$ (TNF- $\alpha$ ), interleukin (IL-) 6 and 10 and alpha-1 antitrypsin (AAT) in pregnant women with current pregnancy loss (CPL) and non-pregnant women with history of RPL compared versus women with normal pregnancy (NP).

\section{Setting}

University hospital, Benha, Egypt

\section{Design}

Prospective comparative double-blinded study

\section{Patients \& Methods}

The current study was conducted at Obstetrics \& Gynecology and Clinical Pathology departments since Jan 2015 till Aug 2016. The study protocol was approved by the Local Ethical Committee. Patients were enrolled in the study after singing a written fully informed consent for 
study precipitation and giving required blood samples.

The study included pregnant women with history of 1st trimester RPL, had no living children and diagnosed as having current spontaneous abortion (CPL group), pregnant women of cross-matched gestational age (GA), had no history of RPL and had at least one living child (NP group) and women with history of 1st trimester RPL, had no living children but had no current pregnancy at time of enrolment in the study (RPL group). Current pregnancy loss (CPL) was defined according to Jurkovic et al. (13) as the loss of a pregnancy before 24 weeks of gestation, irrespective of occurring early ( $\leq 12$ weeks) or late (13-24 weeks).

All women suspected to fulfill the inclusion criteria had full clinical examination for determination of demographic data, previous obstetric history, data of the current pregnancy and then subjected transvaginal ultrasonography (TVU) to ascertain the inclusion criteria for each group, determination of the exact GA and presence of normal fetal cardiac activity for women of NP group.

Exclusion criteria included presence multiple gestation pregnancy, presence of anatomical abnormalities or autoimmune diseases inducing RPL, or failure to detect pregnancy sac, determination of GA on TVU. All women missed any of inclusion criterion were also excluded from the study.

\section{B lood sampling}

All study participants gave $5 \mathrm{ml}$ blood sample that was withdrawn under complete aseptic conditions, allowed to clot and then centrifuged at $3000 \mathrm{rpm}$ for 10 minutes to separate serum that was collected in sterile Eppendorf tube and stores at $-80 \mathrm{oC}$ till be assayed. Blood samples were collected and numbered by a lab assistant who was blinded about diagnosis.

\section{Laboratory investigations}

Serum levels of IL10, IL-6 and TNF- $\alpha$ were measured using enzyme linked immunosorbent assay (ELISA) kits according to the manufacturer's instructions and were read using a 96 well microplate ELISA reader (Dynatech MR 7000).

1- Serum IL-10 was measured using an ELISA kit from Milenia ${ }^{\circledR}$, DPC Biermann, Bad Nauheim; Germany (14).

2- Serum IL-6 (15) and TNF- $\alpha$ (16) levels were measured with an ELISA kit from Pelikine ${ }^{\mathrm{TM}}$ Inc., Concord, USA.

3- Serum AAT was measured with an ELISA kit from Abcam, USA (17).

\section{Statistical analysis}

Obtained data were presented as mean $\pm \mathrm{SD}$, ranges, numbers and percentages. Results were analyzed using One-way ANOVA with post-hoc Tukey HSD Test and Chi-square test (X2 test). Sensitivity \& positive predictive value (PPV; 1specificity) of estimated parameters as predictors were evaluated using the receiver operating characteristic (ROC) curve analysis judged by the area under the curve (AUC) compared versus the null hypothesis that $\mathrm{AUC}=0.05$. Regression analysis (Stepwise method) was used for stratification of studied parameters as specific 
predictors. Statistical analysis was conducted using the SPSS (Version 15, 2006) for Windows statistical package. $\mathrm{P}$ value $<0.05$ was considered statistically significant

\section{Results}

The study included 90 women; 30 in each group.

Patients' enrolment data showed non-significant difference between the three groups (Table 1).

Pregnant women with CPL or non-pregnant women with previous RPL showed significantly disturbed serum levels of estimated proinflammatory and anti-inflammatory cytokines with a more pronounced disturbance in patients of CPL group than women of RPL group. Moreover, serum AAT levels were significantly lower in patients with CPL than patients of other groups with significantly lower levels in patients with past history of RPL (Table 2).

Table (1): Demographic and clinical data of studied women

\begin{tabular}{|c|c|c|c|c|}
\hline \multicolumn{2}{|l|}{ Data } & NP group $(n=30)$ & CPL group $(n=30)$ & $\begin{array}{c}\text { RPL group } \\
(\mathbf{n}=\mathbf{3 0})\end{array}$ \\
\hline \multicolumn{2}{|c|}{ Age (years) } & $26.5 \pm 3.7$ & $26.7 \pm 2.9$ & $27.4 \pm 4.3$ \\
\hline \multirow[t]{3}{*}{ BMI data } & Weight (kg) & $75.4 \pm 14.3$ & $74.3 \pm 9.4$ & $76.9 \pm 12.9$ \\
\hline & Height (cm) & $165.8 \pm 3.4$ & $166 \pm 2.5$ & $166 \pm 3.4$ \\
\hline & BMI $\left(\mathrm{kg} / \mathrm{m}^{2}\right)$ & $27.4 \pm 5.1$ & $26.7 \pm 3.5$ & $27.9 \pm 4.6$ \\
\hline \multicolumn{2}{|c|}{ Gestational age (weeks) } & $9.9 \pm 1.7$ & $10.4 \pm 1.6$ & 0 \\
\hline \multicolumn{2}{|l|}{ Gravidity } & $3.4 \pm 0.6$ & $2.9 \pm 1$ & $2.8 \pm 0.8$ \\
\hline \multicolumn{2}{|l|}{ Parity } & $2.6 \pm 0.9$ & 0 & 0 \\
\hline
\end{tabular}

Data are presented as mean \pm SD; NP group included women with current normal pregnancy; CPL group included women with current spontaneous abortion; RPL group included non-pregnant women with history of recurrent pregnancy loss; BMI: Body mass index; $\mathrm{p}>0.05$ indicates non-significant difference

Table (2): Mean serum levels of parameters estimated in studied women

\begin{tabular}{|l|l|c|c|c|}
\hline \multirow{2}{*}{ Parame ter } & Group & NP group $(\mathbf{n = 3 0})$ & CPL group $(\mathbf{n = 3 0})$ & $\begin{array}{c}\text { RPL group } \\
(\mathbf{n}=\mathbf{3 0})\end{array}$ \\
\hline \multirow{3}{*}{ Serum TNF- $\alpha$} & Level & $3.18 \pm 1.25$ & $7.91 \pm 4.17$ & $5.11 \pm 3.17$ \\
\cline { 2 - 5 } & P1 & & $=0.001$ & 0.048 \\
\cline { 2 - 5 } & P2 & & & 0.0022 \\
\hline \multirow{3}{*}{ Serum IL-6 } & Level & $16.9 \pm 4.12$ & $23.61 \pm 6$ & $20.43 \pm 5$ \\
\cline { 2 - 5 } & P1 & & $=0.001$ & 0.024 \\
\cline { 2 - 5 } & P2 & & & 0.047 \\
\hline \multirow{5}{*}{ Serum IL-10 } & Level & $27.25 \pm 10.1$ & $17.16 \pm 4.52$ & $21.81 \pm 6.69$ \\
\cline { 2 - 5 } & P1 & & $=0.001$ & 0.016 \\
\cline { 2 - 5 } & P2 & & $1.75 \pm 0.35$ & 0.046 \\
\hline & Level & $2.17 \pm 0.5$ & $=0.0019$ & 0.682 \\
\cline { 2 - 5 } & P1 & & & 0.021 \\
\cline { 2 - 5 } & P2 & & & \\
\hline
\end{tabular}

Data are presented as mean $\pm \mathrm{SD}$; NP group included women with current normal pregnancy; CPL group included women with current spontaneous abortion; RPL group included non-pregnant women with history of recurrent pregnancy loss; TNF- $\alpha$ : Tumor necrosis factor- $\alpha$; IL-6: Interleukin-6; IL-10: Interleukin-10; AAT: $\alpha 1$ antitrypsin; P1 indicates significance versus NP group; P2 indicates significance versus SA group; $p<0.05$ indicates significant difference; $p>0.05$ indicates non-significant difference 
Table (3): ROC curve analysis for estimated serum parameters as predictors for pregnancy loss as current or recurrent among studied women

\begin{tabular}{|c|c|c|c|c|c|c|c|c|c|}
\hline \multirow{2}{*}{$\begin{array}{l}\text { Purpose } \\
\text { Parameter }\end{array}$} & \multicolumn{3}{|c|}{ Prediction of current PL } & \multicolumn{3}{|c|}{ Prediction of RPL } & \multicolumn{3}{|c|}{$\begin{array}{c}\text { Prediction for liability for } \\
\text { RPL }\end{array}$} \\
\hline & AUC & $\mathrm{p}$ & IC & AUC & $\mathrm{p}$ & IC & AUC & $\mathrm{p}$ & IC \\
\hline $\begin{array}{l}\text { Serum } \\
\text { TNF- } \alpha\end{array}$ & 0.808 & 0.0008 & $\begin{array}{c}0699- \\
0917\end{array}$ & 0.688 & 0.012 & $\begin{array}{l}0.554- \\
0.823\end{array}$ & 0.717 & 0.004 & $\begin{array}{l}0.587- \\
0.847\end{array}$ \\
\hline $\begin{array}{l}\text { Serum } \\
\text { AAT }\end{array}$ & 0.172 & 0.0007 & $\begin{array}{l}0.071- \\
0.272\end{array}$ & 0.324 & 0.019 & $\begin{array}{l}0.188- \\
0.460\end{array}$ & 0.288 & 0.005 & $\begin{array}{l}0.159- \\
0.417\end{array}$ \\
\hline $\begin{array}{l}\text { Serum IL- } \\
6\end{array}$ & 0.836 & 0.0008 & $\begin{array}{l}0.731- \\
0.356\end{array}$ & 0.627 & 0.092 & $\begin{array}{r}0.479- \\
0.775\end{array}$ & 0.652 & 0.044 & $\begin{array}{l}0.512- \\
0.791\end{array}$ \\
\hline $\begin{array}{l}\text { Serum IL- } \\
10\end{array}$ & 0.234 & 0.0006 & $\begin{array}{l}0.113- \\
0.356\end{array}$ & 0.452 & 0.525 & $\begin{array}{l}0.300- \\
0.604\end{array}$ & 0.313 & 0.013 & $\begin{array}{l}0.178- \\
0.447\end{array}$ \\
\hline
\end{tabular}

AUC: Area under curve; CI: Confidence interval; TNF- $\alpha$ : Tumor necrosis factor- $\alpha$; IL-6: Interleukin-6; IL-10: Interleukin-10; AAT: $\alpha 1$ antitry $p \sin ; \mathrm{p}<0.05$ indicates significant difference; $\mathrm{p}>0.05$ indicates non-significant difference

Table (4): Regression analysis for estimated serum parameters as predictors for pregnancy loss as current or recurrent among studied women

\begin{tabular}{|l|c|c|c|c|c|c|c|c|}
\hline $\begin{array}{l}\text { Statistical } \\
\text { model }\end{array}$ & \multicolumn{2}{|c|}{ Model 1 } & \multicolumn{2}{c|}{ Model 2 } & \multicolumn{2}{c|}{ Model 3 } & \multicolumn{2}{c|}{ Model 4 } \\
\hline Parame ter & $\beta$ & $P$ & $\beta$ & $P$ & $\beta$ & $P$ & $\beta$ & $P$ \\
\hline Serum TNF- $\alpha$ & 0.400 & 0.0009 & 0.477 & 0.0007 & 0.520 & 0.0007 & 0.615 & 0.0004 \\
\hline Serum AAT & -0340 & 0.0008 & -0.389 & 0.0008 & -0.435 & 0.0007 & & \\
\hline Serum IL-10 & -0.242 & 0.004 & -0.267 & 0.003 & & & & \\
\hline Serum IL-6 & 0.226 & 0.014 & & & & & & \\
\hline
\end{tabular}

$\beta$ : Standardized coefficient; TNF- $\alpha$ : Tumor necrosis factor- $\alpha$; IL-6: Interleukin-6; IL-10: Interleukin-10; AAT: $\alpha 1$ antitrypsin; $p<0.05$ indicates significant difference; $p>0.05$ indicates non-significant difference

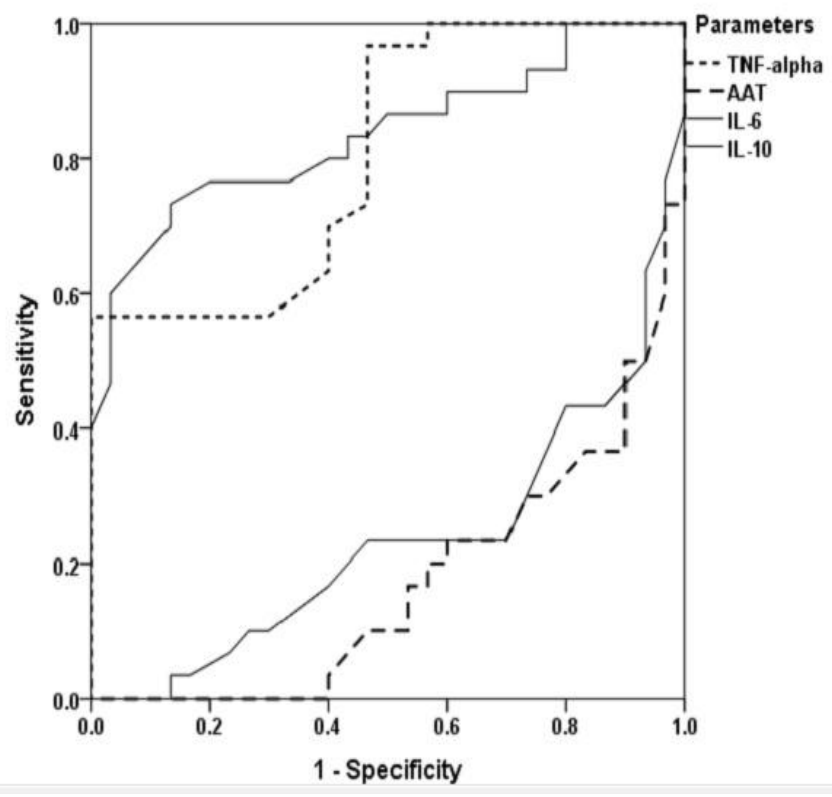

Fig. (1): ROC curve analysis of studied parameters for differentiation between women with NP and CPL

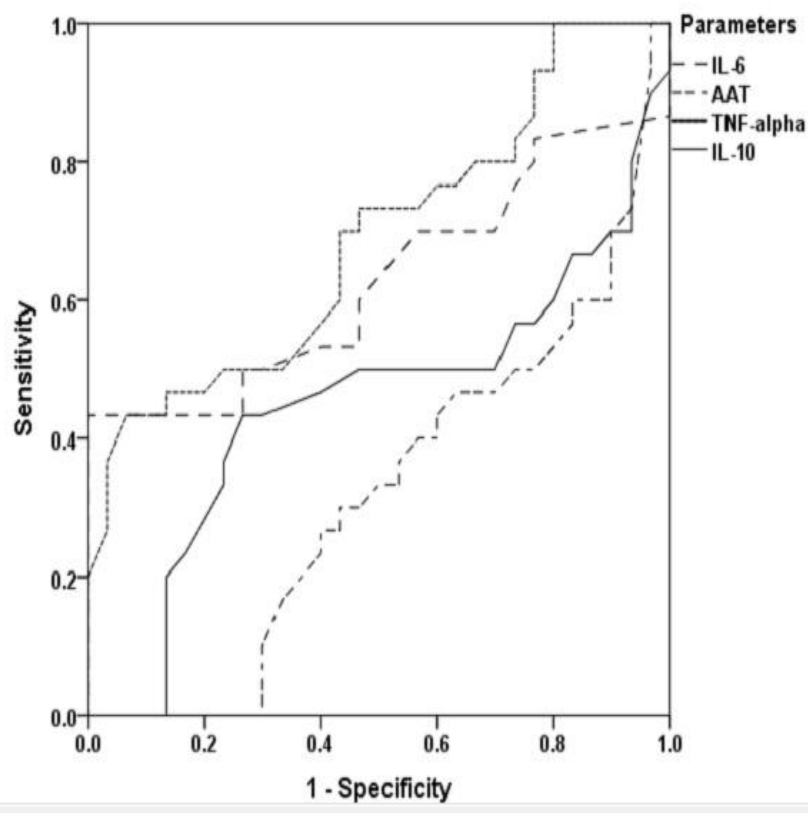

Fig. (2): ROC curve analysis of studied parameters for differentiation between women wi th NP and RPL 


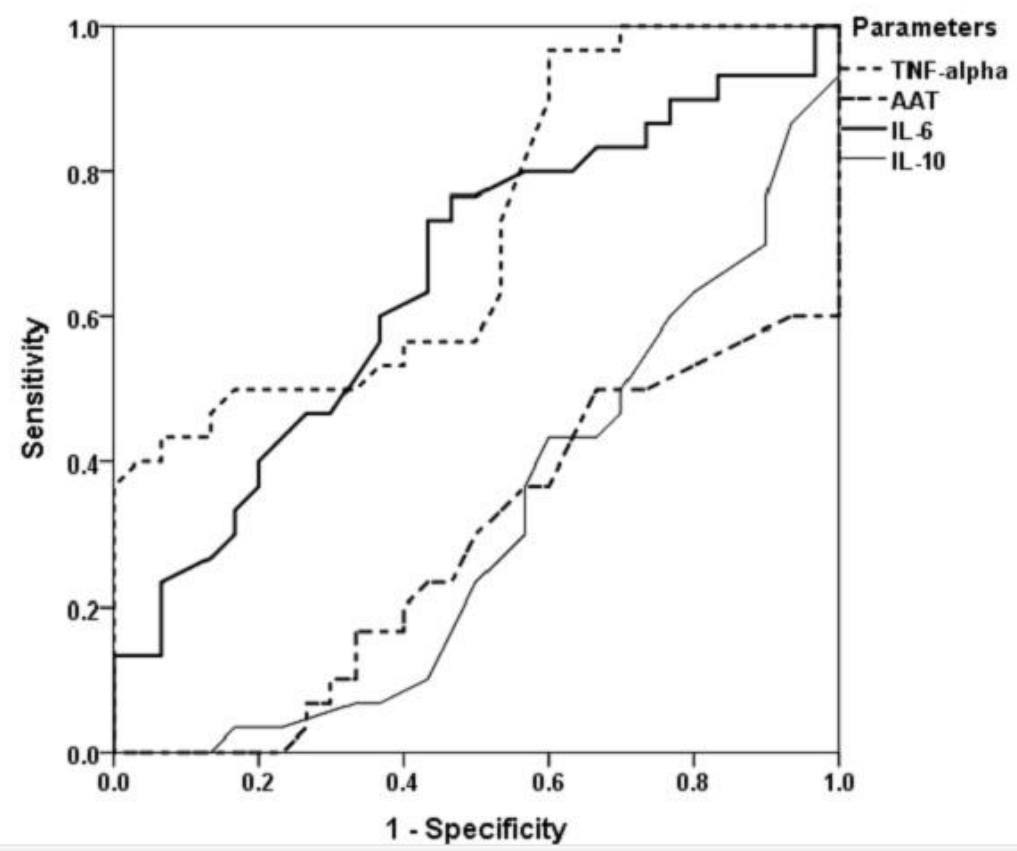

Fig. (3): ROC curve analysis of studied parameters for differentiation between women with RPL and CPL

Statistical analysis using ROC curve for estimated serum parameters for differentiation between studied women defined low serum AAT as a significant sensitive parameter for differentiation between women with current RPL out of women had normal pregnancy (Fig. 1) and non-pregnant women with past history of RPL (Fig. 2) and for differentiation between women with past-history of RPL and normal pregnant women (Fig. 3); so could be used as screening test for presence or liability for development of RPL. On the other hand, high serum levels of TNF- $\alpha$ could differentiate between women with presence or liability to have RPL out of women with normal pregnancy with high positive predictive value, (Tables 3 ).

Regression analysis of estimated parameters for prediction of CPL or liability developing RPL defined serum TNF- $\alpha$ as a specific predictor with persistent significance through the conducted analytical models and serum AAT as a sensitive predictor with persistent significance through the conducted analytical models (Table 4).

\section{Discussion}

Patients with current pregnancy loss (CPL) or past history of recurrent PL (RPL) showed significantly high serum TNF- $\alpha$ and IL-6 levels with significantly lower serum IL-10 levels than normal pregnant (NP) women with significant difference between women of both CPL and RPL groups. These findings spot light on a possible role for disturbed immune milieu in pathogenesis of PL and persistent disturbances may underlie the phenomenon of recurrence.

In line with these data Liang et al, (6) found the ratios of pro-inflammatory and anti-inflammatory cytokines IL-6/IL-10 and TNF- $\alpha /$ TGF- $\beta 1$ were higher in women had recurrent implantation failure (RIF) after IVF/intracytoplasmic sperm injectionembryo transfer, thus suggesting a shift toward a pro-inflammatory state in peripheral blood of the patients with RIF. Galgani et al. (18) documented 
that women with recurrent miscarriage (RM) and RIF showed an increase of circulating proinflammatory cytokines, altered endometrial $\mathrm{T}$ lymphocytes subsets, and signs of endometrial endoplasmic reticulum stress. Also, Ozkan et al. (19) detected a significantly high TNF- $\alpha / \mathrm{IL}-10$, TNF- $\alpha /$ IL-4 and concluded that increased Th1/Th2 cytokine ratios in RPL cases pointed to suppression of anti-inflammatory process that might play an important role in the pathogenesis of idiopathic RPL. Recently, Zhang et al. (20) found baseline TNF- $\alpha$ levels were higher in patients with recurrent spontaneous abortion than in controls.

Moreover, high serum TNF- $\alpha$ showed high AUC in ROC curve analysis for prediction of presence or possibility of recurrence of PL, thus indicating a high positive predictive value for high serum TNF$\alpha$ for a possibility of PL in a woman had recurrent attack. Similarly, Lee et al. (21) found TNF- $\alpha(+)$ Th1 cells and Th1/Th2 cell ratio were highly specific for RPL with AUC $=0.681$ and 0.660, respectively.

In support of the role of disturbed immune milieu in pathogenesis and/or recurrence of PL, Talukdar et al. (22) detected significantly decreased percentage of Th1 cells with significantly decreased levels of IFN- $\gamma$ and TNF- $\alpha$ in the culture supernatant of peripheral blood mononuclear cell (PBMC) from RPL women and treated in vitro with CoQ10 than in untreated cells and attributed this effect to the capability of CoQ10 in reducing oxidative stress by decreasing reactive oxygen species production. Also, Ota et al. (23) experimentally detected significantly decreased Toll-like receptor-4 (TLR4) expression on natural killer (NK) cells and significantly reduced production of TNF- $\alpha$ and
IFN- $\gamma$ on incubation of NK cells of RPL women with di-hydroxy vitamin D3 through interference with nuclear factor-кB. Clinically, Ohams et al. (24) found administration of blockers of phosphodiesterase type 5 or TNF- $\alpha$ blockers before conception seems to be a promising future therapy of immune-dependent RM. Recently, Nasiri \& Rasti (25) and Rasti et al., (26) indicated that polymorphisms of cytotoxic T-lymphocyteassociated protein 4 and IL-6 genes (24) and promoter polymorphism $(-634 \mathrm{C} / \mathrm{G})$ of the IL-6 gene (25) are likely to influence the individual susceptibility to RPL.

Serum levels of AAT, a primary phase reactant with immunomodulatory properties (9), were significantly lower in patients with CPL than NP women and non-pregnant women with RPL. Moreover, serum AAT levels estimated in women of RPL group were significantly lower levels than women of NP group. These findings indicated a role of AAT in maintenance of normal immune balance in uterine microenvironment and a possible role for disturbed AAT level in induction and/or recurrence of pregnancy-related disorders. In support of this assumption, statistical analyses defined low serum AAT as a significant sensitive parameter for differentiation between women with current or previous RPL among pregnant women; so could be used as screening test for presence of or liability for development of RPL.

The reported data and provided assumptions go in hand with previous studies evaluated a possible role for AAT in pathogenesis of pregnancy-related disorders, where Twina et al. (27) found AAT levels were about 2 fold lower in the pre-eclampsia (PE) women compared to healthy women and 
correlated with protease inhibitory capacity and Feng et al. (28) reported that the peripheral AAT content was the highest in the normal fullterm pregnancy, moderate in early-onset $\mathrm{PE}$, and lowest in late-onset LS-PE women. Madar et al. (29) found AAT levels were lower in both recurrent and sporadic SA patients compared with healthy pregnancies and reduced AAT levels correlated with elevated pro-inflammatory cytokines. Hsu et al. (30) reported that immunoassays in serum samples of women with severe PE showed that serum AAT, $\alpha 1$-microglobulin, and clusterin levels of were significantly higher than in normal pregnant women.

Recently, Hsu et al. (31) reported that five proteins including AAT may be involved in the pathogenesis of amniotic fluid of Edwards Syndrome. Also, Kononikhin et al. (32) studied a total of 1786 peptides in urine of 30 women with mild to severe PE and identified AAT, collagen $\alpha$ 1(I) and (III) chains, and uromodulin as peptides that can potentially serve as early indicators of PE. Moreover, Feng et al. (33) suggested that exogenous AAT injection increases the antioxidants and suppresses oxidative stress, and subsequent prevention of $\mathrm{PE}$ development through inactivation of signal transducer and activator of transcription 1/p38 signaling.

\section{Conclusion}

High serum pro-inflammatory with low serum antiinflammatory cytokines levels could diagnose current pregnancy loss with high PPV and persistence of their disturbed levels may predispose to RPL. Activation of primary phase reactant system may underlie, accompany or initiate PL, so low serum AAT during 1st trimester and its persistently low serum levels during interpregnancy intervals could be used as screening test for presence or liability for development of PL.

\section{References}

1. Kaiser J, Branch DW: Recurrent Pregnancy Loss: Generally Accepted Causes and Their Management. Clin Obstet Gynecol. 59(3):464-73, 2016.

2. Amin-Beidokhti M, Mirfakhraie R, ZareKarizi S, Karamoddin F: The role of parental microRNA alleles in recurrent pregnancy loss: an association study. Reprod Biomed Online. 34(3):325-330, 2017.

3. Hu XH, Tang MX, Mor G, Liao AH: Tim-3: Expression on immune cells and roles at the maternal-fetal interface. J Reprod Immunol.118:9299, 2016

4. Triggianese P, Perricone C, Chimenti MS, De Carolis C, Perricone R: Innate Immune System at the Maternal-Fetal Interface: Mechanisms of Disease and Targets of Therapy in Pregnancy Syndromes. Am J Reprod Immunol. 76(4):245-57, 2016

5. Zhu L, Chen H, Liu M, Yuan Y, Wang Z, Chen Y, Wei J, Su F, Zhang J: Treg/Th17 Cell Imbalance and IL-6 Profile in Patients With Unexplained Recurrent Spontaneous Abortion. Reprod Sci. 24 (6), 882-890. 2016

6. Liang PY, Diao LH, Huang CY, Lian RC, Chen X, Li GG, Zhao J, Li YY, He XB, Zeng Y:

The pro-inflammatory and anti-inflammatory cytokine profile in peripheral blood of women with recurrent implantation failure. Reprod Biomed Online 31(6):823-6, 2015 
7. Huangfu C, Zhang J, Ma Y, Jia J, Lv M, Zhao X, Zhang J: New process for purifying high purity $\alpha 1$-antitrypsin from Cohn Fraction IV by chromatography: A promising method for the better utilization of plasma. J Chromatogr B Analyt Technol Biomed Life Sci. 1046:156-164, 2017

8. Henao MP, Craig TJ: Understanding alpha-1 antitrypsin deficiency: A review with an allergist's outlook. Allergy Asthma Proc. 38(2):98-107, 2017

9. Guttman O, Freixo-Lima GS, Kaner Z, Lior Y, Rider P, Lewis EC: Context-Specific and Immune Cell-Dependent Antitumor Activities of $\alpha 1$-Antitrypsin. Front Immunol. 7:559, 2016

10. Zemel R, Bachmetov L, Ad-El D, Abraham A, Tur-Kaspa R: Expression of liver-specific markers in naïve adipose-derived mesenchymal stem cells. Liver Int. 29(9):1326-37, 2009

11. Takashima $\mathbf{S}$, Ise $\mathbf{H}$, Zhao $\mathbf{P}$, Akaike T, Nikaido T: Human amniotic epithelial cells possess hepatocyte-like characteristics and functions. Cell Struct Funct. 29(3):73-84, 2004

12. Izumi-Yoneda N, Toda A, Okabe M, Koike C, Takashima S, Yoshida T, Konishi I, Saito S, Nikaido T: Alpha 1 antitrypsin activity is decreased in human amnion in premature rupture of the fetal membranes. Mol Hum Reprod. 15(1):4957, 2009

13. Jurkovic D, Overton C, Bender-Atik R: Diagnosis and management of first trimester miscarriage. BMJ. 346:f3676, 2013

14. Poll T: IL-10 release during endotoxaemia in chimpanzees: role of platelet-activating factor and IL-6. Scand. J Immunol. 1996; 43: 122
15. Gaines-Das RE, Poole S: The international standard for interleukin-6 - evaluation in an international collaborative study. J Immunol Methods. 160: 147-53, 1993

16. De Kossodo S, Houba V, Grau GE: the WHO Collaborative Study Group. Assaying tumor necrosis factor concentrations in human serum. A WHO international collaborative study. J Immunol Methods. 182:107-14, 1995

\section{Miyake M, Ross S, Lawton A, Chang M, Dai} Y, Mengual L, Alcaraz A, Giacoia EG, Goodis on S, Rosser CJ: Investigation of CCL18 and A1AT as potential urinary biomarkers for bladder cancer detection. BMC Urol. 13:42, 2013

18. Galgani M, Insabato L, Calì G, Della Gatta AN, Mirra P, Papaccio F, Santopaolo M, Alviggi C, Mollo A, Strina I, Matarese G, Beguinot F, De Placido G, Ulianich L: Regulatory $\mathrm{T}$ cells, inflammation, and endoplasmic reticulum stress in women with defective endometrial receptivity. Fertil Steril. 103(6):1579-86, 2015

19. Ozkan ZS, Deveci D, Simsek M, Ilhan F, Risvanli A, Sapmaz E: What is the impact of SOCS3, IL-35 and IL17 in immune pathogenesis of recurrent pregnancy loss? J Matern Fetal Neonatal Med. 28(3):324-8, 2015

20. Zhang C, Deng X, Zhang X, Pan Z, Zhao W, Zhang Y, Li J, Xiao F, Wu H, Tan H, Guo P, Yang X: Association between Serum TNF- $\alpha$ Levels and Recurrent Spontaneous Miscarriage: A Metaanalysis. Am J Reprod Immunol. 75(2):86-93, 2016

21. Lee SK, Na BJ, Kim JY, Hur SE, Lee M, Gilman-Sachs A, Kwak-Kim J: Determination of clinical cellular immune markers in women with 
recurrent pregnancy loss. Am J Reprod Immunol. 70(5):398-411, 2013

22. Talukdar A, Sharma KA, Rai R, Deka D, Rao DN: Effect of Coenzyme Q10 on Th1/Th2 Paradigm in Females with Idiopathic Recurrent Pregnancy Loss. Am J Reprod Immunol. 74(2):169-80, 2015

23. Ota K, Dambaeva S, Kim MW, Han AR, Fukui A, Gilman-Sachs A, Beaman K, KwakKim J: 1,25-Dihydroxy-vitamin D3 regulates NKcell cytotoxicity, cytokine secretion, and degranulation in women with recurrent pregnancy losses. Eur J Immunol. 45(11):3188-99, 2015

24. Ohams M, Jerzak M, Górski A: Effects of sildenafil citrate and etanercept treatment on TNF- $\alpha$ levels in peripheral blood of women with recurrent miscarriage. Ginekol Pol. 86(7):520-4, 2015

25. Nasiri M, Rasti Z: CTLA-4 and IL-6 gene polymorphisms: Risk factors for recurrent pregnancy loss. Hum Immunol. 77(12):1271-1274, 2016

26. Rasti Z, Nasiri M, Kohan L: The IL-6 634C/G polymorphism: a candidate genetic marker for the prediction of idiopathic recurrent pregnancy loss. Int J Reprod Biomed (Yazd).14(2):103-8, 2016

27. Twina G, Sheiner E, Shahaf G, Yaniv Salem S, Madar T, Baron J, Wiznitzer A, Mazor M, Holcberg G, Lewis EC: Lower circulation levels and activity of $\alpha-1$ antitrypsin in pregnant women with severe preeclampsia. J Matern Fetal Neonatal Med. 25(12):2667-70, 2012

28. Feng YL, Zhou CJ, Li XM, Liang XQ: Alpha-1-antitrypsin acts as a preeclampsia-related protein: a proteomic study. Gynecol Obstet Invest. ;73(3):252-9, 2012

29. Madar T, Shahaf G, Sheiner E, Brazg J, Levinson J, Yaniv Salem S, Twina G, Baron J, Mazor M, Holcberg G, Lewis EC: Low levels of circulating alpha-1 antitrypsin are associated with spontaneous abortions. J Matern Fetal Neonatal Med. 26(18):1782-7, 2013

30. Hsu TY, Hsieh TT, Yang KD, Tsai CC, Ou CY, Cheng BH, Wong YH, Hung HN, Chou AK, Hsiao CC, Lin H: Proteomic profiling reveals $\alpha 1$-antitrypsin, $\alpha 1$-microglobulin, and clusterin as preeclampsia-related serum proteins in pregnant women. Taiwan J Obstet Gynecol. 54(5):499-504, 2015

31. Hsu TY, Lin H, Hung HN, Yang KD, Ou CY, Tsai CC, Cheng HH, Chung SH, Cheng BH, Wong YH, Chou AK, Hsiao CC: TwoDimensional Differential Gel Electrophoresis to Identify Protein Biomarkers in Amniotic Fluid of Edwards Syndrome (Trisomy 18) Pregnancies. PLoS One. 2016; 11(1):e0145908.

32. Kononikhin AS, Starodubtse va NL, Bugrova AE, Shirokova VA, Chagovets VV, Indeykina MI, Popov IA, Kostyukevich YI, Vavina OV, Muminova KT, Khodzhaeva ZS, Kan NE, Franke vich VE, Nikolaev EN, Sukhikh GT: An untargeted approach for the analysis of the urine peptidome of women with preeclampsia. J Proteomics. 149:38-43, 2016

33. Feng Y, Xu J, Zhou Q, Wang R, Liu N, Wu Y, Yuan H, Che H: Alpha-1 Antitrypsin Prevents the Development of Preeclampsia Through Suppression of Oxidative Stress. Front Physiol. 7:176, 2016 